\section{Knotting of guide wires during esophageal dilation}

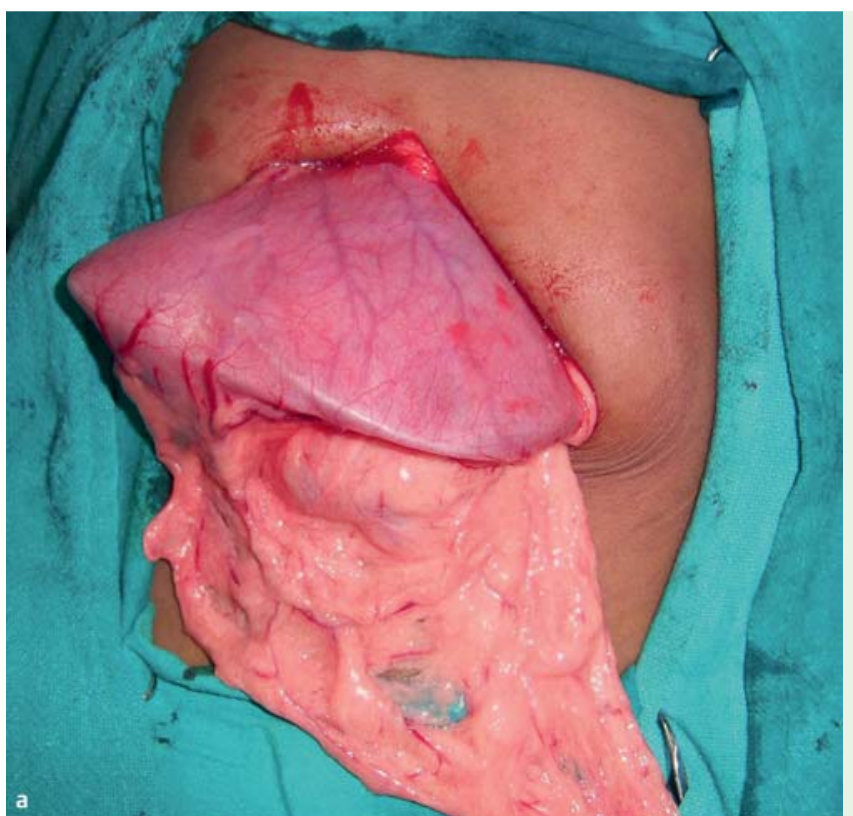

Fig. 1 a Coiled and knotted guide wire in the stomach. $\mathbf{b}$ Guide wire retrieved through gastrotomy.

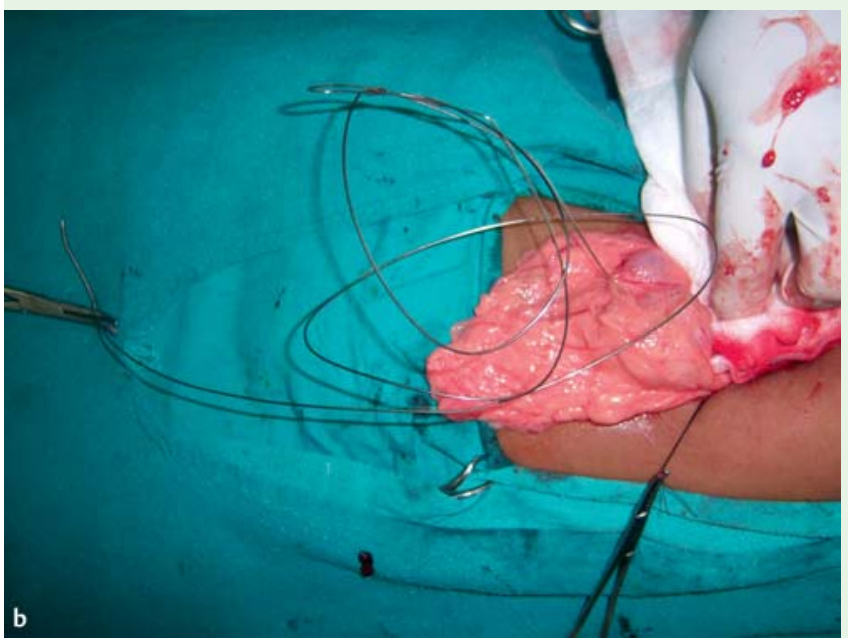

Guide wire-directed esophageal dilation is associated with complications related to procedure and instrumentation. We report on two cases in which the guide wires could not be retrieved due to intragastric knotting and which necessitated surgical intervention.

Two children, a 3-year-old boy and a 4year-old girl, presented separately with history of ingestion of corrosive substances and progressive dysphagia. Endoscopy revealed strictures at the lower end of the esophagus and endoscopic dilation was planned. After informed consent, esophageal dilation was performed under sedation and constant monitoring. A stainless steel unmarked guide wire was used in the first case, and a coated flexible unmarked guide wire was used in the second. The endoscopist could not retrieve
Failed placement of the device and perforation are the common guide wirerelated risks during procedures in the gastrointestinal tract [4]. Buckling, kinking, and knotting is more commonly seen with flexible-tip guide wires than stiff guide wires. Knotting can occur when an excessive length of wire is inserted and when there is a transfer of force on the endoscope to the guide wire.

We encountered knotting with both stainless steel and flexible-coated guide wires, probably due to insertion of an excessive length of guide wire. Knotting and kinking of the catheter can be prevented by insertion of an appropriate length of guide wire, use of stiffer wires, and gentle movement of the endoscope. We recommend the use of marked guide wires and sensitization and training of the technical assistant to avoid such complications.

\section{Competing interests: None}

\section{Endoscopy_UCTN_Code_CPL_1AH_2AF}

A. Mohta ${ }^{1}$, V. Manchanda ${ }^{1}$, M. Yadav ${ }^{2}$

1 Department of Pediatric Surgery, Chacha Nehru Bal Chikitsalaya (affiliated with Maulana Azad Medical College), Geeta Colony, Delhi-110031, India

2 Department of Pediatrics, Chacha Nehru Bal Chikitsalaya (affiliated with Maulana Azad Medical College), Geeta Colony, Delhi-110031, India

\section{References}

1 Somogyi L, Chuttani R, Croffie J et al. Guidewires for use in GI endoscopy. Gastrointest Endosc 2007; 65: 571 - 576

2 Reddy SC, Draganov PV. ERCP wire systems: the long and the short of it. World J Gastroenterol 2009; 15: 55-60

3 Fleischer DE, Benjamin SB, Cattau ELJr et al. A marked guide wire facilitates esophageal dilatation. Am J Gastroenterol 1989; 84: 359-361

4 Clouse RE. Complications of endoscopic gastrointestinal dilation techniques. Gastrointest Endosc Clin N Am 1996; 6: 323-341

\section{Bibliography}

DOI 10.1055/s-0029-1244049

Endoscopy 2010; 42: E141

(c) Georg Thieme Verlag KG Stuttgart · New York . ISSN 0013-726X

\section{Corresponding author}

\section{A. Mohta, MD}

28-B, Pocket-C, S.F.S. Flats

Mayur Vihar Phase-III

Delhi-110096

India

Fax: +91-11-22042750

mohtaanup@hotmail.com 